\title{
Understanding employees' responses to artificial intelligence
}

\author{
Yu-Qian Zhu, Jacq ueline Corbett, Yi-Te Chiu
}

In recent years, artificial intelligence (AI) has moved from buzzword to rapid adoption across the globe. Nearly half of the respondents in a 2018 McKinsey survey of global firms said their organizations have embedded at least one application of $\mathrm{Al}$ into their standard business processes, while another 30\% report piloting the use of Al (Selected bibliography 1). The advancing capabilities of Al are driving business transformation at multiple levels, from tasks and occupations to operational processes and business models. Leveraging Al has become a necessity for organizations hoping to elevate their performance and create a competitive advantage. The rapid rollout of $\mathrm{Al}$ applications is creating new stress for employees and how they respond whether employees lead or flee - will influence the success of Al implementation projects. Before discussing the different Al profiles and how these translate into actions, we present a brief introduction to the technology.

\section{INTRODUCTION TO ARTIFICIAL INTELLIGENCE}

Many definitions exist for Al, but broadly speaking, $\mathrm{Al}$ involves the use of digital technology to perform tasks that have typically required human intelligence. Al is not a single technology, but an array of software and programs that can be embedded within a vast number of applications. Applications of Al are classified based on how the machine's cognitive capabilities compare to human intelligence. The applications of $\mathrm{Al}$ in use today represent artificial narrow intelligence (ANI). With ANI, the system is able to perform a specific task autonomously using human-like capabilities, like machine learning $(M L) . M L$ is a system that is able to learn how to perform given tasks without being given specific directions. These systems are trained with large data sets from which they identify previously unobserved patterns in order to make optimal decisions within a given set of constraints. Common applications of $\mathrm{ML}$ include digital service agents, chatbots with speech and language recognition capabilities, self-driving cars with embedded visual recognition, routines for identifying fake news or inappropriate social media content, and recommender systems in online shopping or service platforms.

Two further types of Al are proposed beyond ANI: artificial general intelligence (AGI) and artificial superintelligence (ASI). Although real-world examples are rare, AGI and ASI are portrayed in films where machines are given extraordinarily human cognitive and emotional capabilities. AGI is the ability of a machine to learn, perceive, understand, and function completely like a human. Machines having AGI have multi-functional capabilities allowing them to adapt to different situations and perform a range of tasks for which they have not been trained. With AGI, machine intelligence is on par with the adaptable intellect of humans. On the cognitive capability continuum, ASI takes a step further than AGI because, at the level of superintelligence, machines will be exceedingly better than their human counterparts at almost everything. Machines with ASI will be equipped with immensely greater memory along with faster data processing, analysis, and decision-making capabilities, giving them almost unlimited capabilities. While the arrival of AGI and ASI is not imminent, Stuart Russell, a renowned Al researcher at the University of California, Berkeley, draws an analogy between Al with nuclear technologies and emphasizes the need to consider risks ahead of the realization of advanced $\mathrm{Al}$ (Selected bibliography 2). He is not alone as many others share similar concerns.

\section{CONCERNS REGARDING ARTIFICIAL INTELLIGENCE}

"If Al has a goal and humanity just happens to be in the way, it will destroy humanity as a matter of course without even 
thinking about it . . . " Elon Musk, as quoted in "Do you trust this computer" by Chris Paine.

Stuart Russell and Elon Musk are just two of many thought leaders who have raised alarms regarding the impact of Al. Fortunately, the world of Al described above remains hypothetical as ASI is still decades away. Still, the potential for ASI brought to life with fantastical portrayals in the movies can cause people to worry about the future of humanity.

In the present, applications of Al, even though narrow, create real and immediate concerns for organizations and individuals. The omnipresence of Al has raised anxieties around data security, ethics, and privacy, as the technology challenges traditional concepts of consent and defined use. Further, ML-enabled automation and other applications of Al will inevitably replace human workers in many jobs. Research by the University of Oxford and World Bank suggests, at the high-end, 40$60 \%$ of the workforce is susceptible to unemployment caused by technology (selected bibliography 3). Even professionals who are less likely to be replaced by Al, such as healthcare workers, sales representatives, and software developers, will be required to partner and cowork with intelligent technologies. As a result, work dynamics within organizations will inevitably change. Many employees will experience feelings of loss of power and control and the implementation of algorithmic management could erode trust in employer-employee relations. To harness the positive potential of Al, getting employees 'on board' will be essential. Like prior implementations of enterprise systems, Al will naturally encounter employee resistance, but three conditions suggest the situation may be more challenging this time around.

\section{More questions than answers}

Although many large organizations have started to experiment with Al, a majority of businesses are still in the preadoption phase. This phase is crucial as it sets the stage for future implementation efforts. Strong negative attitudes formed by employees or other stakeholders (e.g., customers) during this period subsequently become more difficult to change. Unfortunately for many organizations, there are more questions than answers when it comes to Al. Employees - from top management to front-line personnel - still have limited direct working experience with Al, so their impressions of Al come largely from what they read or hear through professional magazines, mass media, movies, and personal social networks. These sources of information, particularly the latter, may also be sources of misinformation. Furthermore, many important considerations, such as regulatory frameworks and appropriate use (e.g., self-driving cars), have yet to be resolved which create additional uncertainty for organizations and employees.

\section{Al triggers rational and strong emotional attitudes}

Employees' reactions to Al, whether they choose to wholeheartedly accept or resist the technology, are driven by attitudes. As we explain in the next section, attitudes comprise both rational evaluations and emotional responses. With Al, emotional responses may be emphasized because the deep learning and human-like characteristics embedded in $\mathrm{Al}$ (e.g., avatars, personal assistants, robots) threaten to upset human-human and human-machine relationships. The advancing capabilities and ubiquity of $\mathrm{Al}$ also raise fundamental questions about the future of society that do not arise from other enterprise technologies. People, therefore, develop attitudes toward Al not just as employees, but also as members of society.

\section{Employees will not be passive adopters of Al}

Within organizations, the use of some Al applications (e.g., personal assistants) may be voluntary, but many others (e.g., automation) will be required as part of the employment contract or business processes. Still, managers cannot expect today's employees to accept passively the consequences that befall them. Empowered by the Internet and social media, employees have reclaimed their personal agency. Employees have greater job mobility and those who are not satisfied with their organization's approach to Al can seek opportunities elsewhere. This creates a crucial challenge for organizations because the availability of skilled people to implement Al effectively is a key factor in project success. Moreover, recovering lost organizational knowledge is nearly impossible and recruiting skilled workers from outside the organization is expensive. For these reasons, managers must be able to decipher their employees' attitudes toward Al, understand how those attitudes are likely to influence behaviors, and then put in place appropriate measures to retain and motivate employees to ensure the effective implementation of enterprise Al.

\section{COGNITIVE APPRAISAL THEORY FOR COPING WITH STRESS}

According to the popular Cognitive Appraisal Theory, when faced with a stressful situation, people's thoughts, feelings, and behavioral responses are influenced by their cognitive appraisals of such situations (Selected bibliography 4). Thus, even before having direct workplace experience with $\mathrm{Al}$, employees are forming attitudes that will influence how they react to Al projects. As illustrated in Fig. 1, employees receive information about $\mathrm{Al}$ from a variety of different sources: traditional and social media, business press and trade magazines, messaging from their employers, coworkers, friends and family, and personal experience with Al. Based on this information, employees evaluate the capabilities and potential consequences of $\mathrm{Al}$, resulting in attitudes.

Attitudes have both a rational (what I think) and an emotional part (what I feel). Rationally, employees consider the potential cost-benefit trade-off of Al investments for their organization, such as whether Al will provide increased efficiency and profitability. At an emotional level, employees experience different feelings related to Al. Anxiety and stress come along with perceived threats and challenges, whereas interest and excitement emerge with perceived 


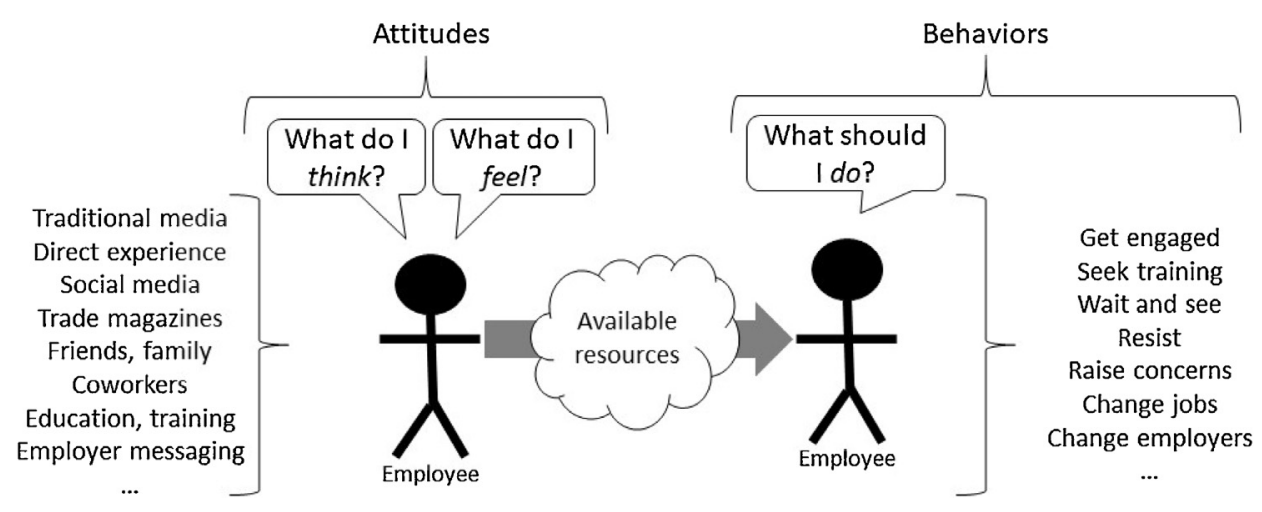

Fig. 1 Forming Attitudes and Behaviors Toward Al

opportunities. Employees may possess mixed attitudes toward transformative technologies like Al: they see the business benefits of $\mathrm{Al}$, but at the same time feel worried about the potential negative consequences on their work and society.

The cognitive and emotional attitudes formed during the initial appraisal of a situation influence a person's subsequent behaviors. This occurs through a secondary appraisal process through which a person considers whether she/he possesses the necessary abilities and resources to cope. The availability of resources leads to either problem-focused coping or emotion-focused coping responses. Employees who have many resources (e.g., personal knowledge, social supports, or other tools) usually feel less threatened and, as a result, will engage more fully in Al implementations. Alternatively, employees who lack resources or feel a loss of control because of the introduction of Al might adopt defensive, emotional strategies, such as resistance or withdrawal (Selected bibliography 5).

\section{EMPLOYEES’ ATTITUDES TOWARD AI: FOUR PROFILES}

Employee attitudes toward Al can vary along two dimensions, rational attitudes and emotional attitudes, from less to more positive. The rational dimension of attitudes arises from a logical evaluation of Al, its capabilities, and potential. When employees believe that Al possesses capabilities to support their jobs, by improving productivity or reducing routine activities, positive rational attitudes are formed. On the contrary, when employees think Al will diminish their job performance or interrupt work routines, their rational attitudes will be less positive. This may occur, for instance, when ML algorithms operate within a "black box", such that employees are unable to verify the logical reasoning, leading to distrust of the resulting decisions or recommendations (Selected bibliography 6).

In contrast to rational attitudes, emotions are not the result of a deliberative process. Emotions are complex psychological states that emerge naturally in response to different stimuli. Emotions can range from positive feelings of happiness, love, and surprise, to negative emotions of anger, fear, and sadness. Positive emotions related to Al may arise from optimism about the future of the technology, eagerness to explore its capabilities and transformative potential, and amazement at its rapid advancement. On the other hand, negative emotions arise when people see potential future loses or feel threatened. Fear is a frequently expressed negative emotion when talking about Al because people are nervous and uneasy about how the future of Al will unfold. Still, others may feel sympathy for other people

Table 1 About the Research

Data collection

Survey participants

Interview participants
We engaged a reputable market research firm in Taiwan to administer the survey. The survey contained questions related to the employees' perceptions of Al, rational and emotional attitudes, and behavioral intentions. Most questions were answered based on a five-point scale. Statistical techniques were applied to develop the profiles.

Of the 363 participants, $55 \%$ were women. Half (50\%) were between 30 to 39 years old, $26 \%$ were 40 to 49 , and $16 \%$ were 20 to 29 . The participants worked in a variety of industries, including services (31\%), manufacturing $(27 \%)$, information technology $(11 \%)$, government $(10 \%)$, and finance $(4 \%)$. The majority of participants $(81 \%)$ were in non-management positions and $59 \%$ did work that was more knowledge intensive.

The first author recruited interview participants through a major Taiwanese university. Interviewees were from organizations in the pre and early adoption phases of Al. Five of the eight interviewees were men, six worked in the finance sector, five were in management positions, and six held jobs that were less knowledge intensive. Questions on the interviews covered themes similar to the survey. 


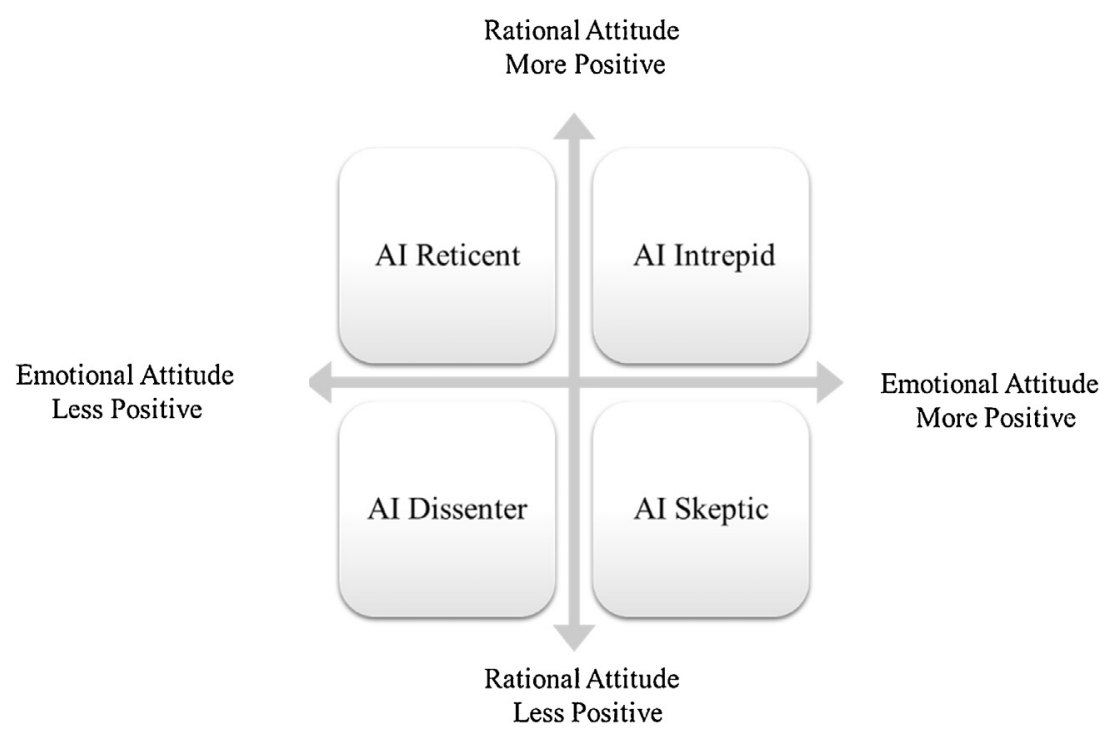

Fig. 2 Profiles of Employees' Attitudes Toward Al

displaced by $\mathrm{Al}$ or anger and bitterness with respect to their employers' decisions to use Al for monitoring their performance.

To investigate employees' attitudes and responses to $\mathrm{Al}$, we conducted a survey of 363 employees whose organizations were likely to implement Al in the future. To complement the survey with qualitative richness, we also interviewed eight employees dealing with the arrival of $\mathrm{Al}$ in their workplaces (details regarding the research are provided in Table 1). From the data collected and using the rational and emotional dimensions as anchors, we identified four profiles of employees' attitudes toward Al as illustrated in Fig. 2. The diversity of the survey participants means the findings are likely to apply across industry sectors in highly industrialized countries.

Al Reticents are people who, on a rational level, see Al as a valuable, beneficial, or wise investment for their organization, but who hold less positive (and sometimes negative) feelings toward the technology. In our sample, this was the smallest group of employees, making up about $8 \%$. When discussing the potential implementation of $\mathrm{Al}$, Reticients acknowledge the potential commercial benefits of the technology, but are reluctant to embrace it because of feelings of fear, a bad "gut feeling", or other unease.
Al Intrepids eagerly welcome Al with both their minds and their hearts. About $36 \%$ of the employees we surveyed could be considered Al Intrepids. They recognize the value and potential benefits of Al and, emotionally, feel optimistic, excited, or energized by this new technology. Intrepids are most likely to lead the charge in implementing Al because they are "all in" with the technology.

The Al Skeptics share the Intrepids' emotional positivity about Al, but fail to see the practical value of the technology for their organization. Skeptics make up about $10 \%$ of the employee population based on our survey. This less positive rational evaluation may be driven by the strategic or operational environment of the organization. For instance, a Skeptic might evaluate that the costs of implementing Al are too high as compared to the operational savings, or that Al applications would not add significant competitive advantage. Skeptics are likely to express interest and optimism about Al, but still argue against its implementation until the commercial payoffs are more evident.

Al Dissenters are people whose attitudes - both rational and emotional - are least positive toward Al. Al Dissenters made up $46 \%$ of employees in our sample. Dissenters evaluate $\mathrm{Al}$ as having little or no meaningful business value and have stronger negative emotional reactions to the technology. Some Dissenters may take an active role in voicing

Table 2 Details of Employee Profiles

\begin{tabular}{llllll}
\hline Profile & Characteristics & & & \\
& Technology & Perceived cognitive & Perceived operational & Anticipated adverse & Knowledge \\
& optimism & capabilities of Al & capabilities of Al & outcomes of Al & intensity of work \\
Al Reticent & Average & High & High & High & Low \\
Al Intrepid & High & High & High & Average & High \\
Al Skeptic & Average & Low & Average & Average & Average \\
Al Dissenter & Low & Average & Low & Average & Average \\
\hline
\end{tabular}


concerns and opposing Al, while others may be more discreet and passively resist efforts to leverage Al within their work environment.

\section{Differences between the four employee profiles}

While differences between rational and emotional attitudes define the four profiles, five characteristics help to explain which employees will fall into each category. Perhaps surprisingly, the employee's age, gender, position (managerial vs. non-managerial) do not significantly vary across the four profiles. Instead, there are differences in the employees' technology optimism, perceptions of cognitive and operational capabilities of $\mathrm{Al}$, anticipated adverse outcomes of $\mathrm{Al}$, and knowledge intensity of the employees' work, as summarized in Table 2.

Occupying the top half of Fig. 2, Al Reticients and Al Intrepids have more positive rational attitudes toward Al. Employees in these groups believe Al has high operational and cognitive capabilities. These employees agree $\mathrm{Al}$ is reliable and able to meet a variety of needs and integrate data from different areas of the business (operational capabilities). Reticients and Intrepids also agree Al applications can process human language effectively, handle contextual ambiguity, and follow a clear logic to arrive at conclusions (cognitive capabilities). At an individual level, Reticients and Intrepids have average to high technology optimism, indicating they perceive new technologies to be useful and easy to use. Thus, personal technology optimism combined with positive perceptions of Al capabilities leads to the development of positive rational attitudes.

Although Reticients and Intrepids share positive rational attitudes, they diverge in their emotional attitudes toward Al. Two factors contribute to this difference: their expectation for adverse outcomes from Al and the knowledge intensity of their work. As Table 2 shows, Al Reticents have the highest concerns about negative Al outcomes across all four groups. This means they are worried about changes in their job content and their ability to use new Al applications. Reticents also have substantial concerns regarding the detri- mental effects of Al on human relationships and humanity. These concerns tend to evoke more emotional responses, particularly negative ones of fear and anxiety. For Reticients, negative emotions are amplified because their work is labor-intense, making them good targets to be replaced as Al automation rolls out across the organization. Al Intrepids, on the other hand, are not overly concerned about the negative consequences of Al. As they tend to occupy knowledge-intensive jobs, Intrepids feel excited and motivated by $\mathrm{Al}$, rather than threatened by it, because they see new avenues for extending and enhancing their work by leveraging $\mathrm{ML}$ and other Al applications.

In the bottom half of Table 2, Al Skeptics and Al Dissenters hold less positive rational attitudes toward Al, suggesting they have a harder time seeing the concrete benefits Al will bring to their organization. Skeptics and Dissenters perceive the capabilities of Al as being low to average, are not bullish on technology in general, have average concerns regarding the adverse impacts of $\mathrm{Al}$, and occupy positions requiring some knowledge work.

On an emotional level, Al Skeptics are more positive than Al Dissenters. Skeptics are not technology pessimists and do not feel their jobs are specifically threatened. But, they also do not believe that Al has reached a high level of cognitive capability yet. Their positive emotions most likely reflect feelings of anticipation as Al capabilities continue to evolve. In contrast, Al Dissenters are the most pessimistic about technology. Naturally, they view new technologies with caution and disagree that new technologies are easy to use and give people more control over their lives. When technology pessimism is coupled with low evaluative judgements of Al's capabilities, Dissenters have feelings of apprehension, annoyance, despair, and apathy, reflecting a less positive emotional attitude toward Al.

\section{HOW EMPLOYEE ATTITUDES INFLUENCE BEHAVIORS}

When coping with a stressful situation, people can behave in many different ways depending on their cognitive appraisal

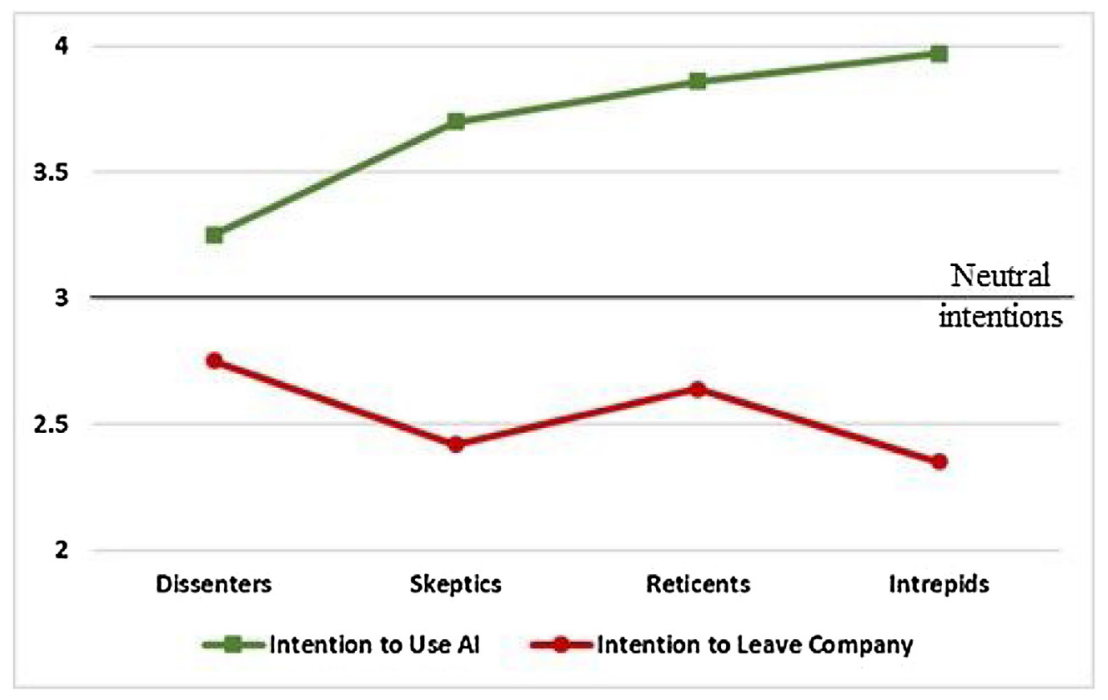

Fig. 3 Employee Responses by Profile 
of the situation. Our research investigated two opposing behavioral responses employees might have to $\mathrm{Al}$ : using $\mathrm{Al}$ applications and leaving the organization. Fig. 3 plots the average responses for the four profiles, based on a 5-point scale with 1 being very unlikely and 5 being very likely.

This graph shows that Dissenters are most undecided in terms of how they will respond to Al. Both their intentions to use $\mathrm{Al}$ and intentions to leave are close to neutral, meaning they remain on the fence, unsure of whether to engage or withdraw from the stress-causing situation. On the other hand, Intrepids' behavioral response is more certain, as they are most likely to use $\mathrm{Al}$ and least likely to leave their companies. Using insights from our interviews, we now elaborate on how each group of employees is coping with the introduction of Al.

\section{Al Dissenters struggle to adapt}

At $46 \%$, the Dissenters represent the biggest category of employees in our sample, highlighting a potential impediment to successful Al adoption. At a rational level, a key concern for Dissenters relates to the potential for job losses. Managers in this group do not believe the efficiencies gained by $\mathrm{Al}$, such as achieved through automation and replacement of workers, will be enough to offset the trouble, risks, and negative impacts on employee morale that come from job reductions. There is also concern regarding the effect of $\mathrm{Al}$ on the headcounts in their departments. As an IT Director of a major bank observed:

"In the beginning, there is a resistance phase from top managers. They are afraid that Al implementation will impact their frontline employees, and therefore, their headcounts."

As departmental budgets and performance are often tied to staffing levels, managers are concerned their capacity to achieve desired objectives might be reduced with the introduction of Al.

Dissenters also express concerns triggering negative emotional attitudes. Certainly, the fear of job loss is present, but there is also more nuanced unease regarding perceptions of justice and privilege in terms of whose job is spared and whose job is saved. Even without the threat of layoffs, Dissenters are worried about how current jobs are transformed with Al. An administrative manager from a large telecom company with a non-layoff policy offered an analogy to illustrate the challenge:

"Like math, you can probably get a pass through hard work, but to get to an A you need some gift. Most people are not gifted. There are only a limited number of people at the top percentile. When the technology impacts the majority of people at the [middle of the] curve, then there is going to be very strong resistance. What are they going to do?"

The manager does not question the value of Al from the business perspective, but expresses feelings of insufficiency associated with the lack of intellectual capacity to keep up with machines, creating personal stress and negative attitudes toward Al. Not all positions will require "top percentile" intelligence, but people will still find it hard to adapt, leading to a range of different outcomes, which may include leaving the organization. A bank clerk to whom we spoke reported that she, like many others, was encouraged to retrain as a financial advisor because operational staff were no longer in demand. She observed the following reactions within her organization:

"You've been inculcated about the transformation, [ . . . ] so if you really can't do it, if you can't meet the goals they set, you have mounting pressure and you'll naturally leave in industry. Some of them [senior staff] retire, or go back to help their family, or find other jobs. Some young clerks are not taking this well either. [They think] 'I just want to be a bank clerk, why do you force me to do this?' So they would change industry, apply for government jobs, or apply for state-owned banks."

\section{Al Intrepids eager to engage with Al}

Diametrically opposed to Dissenters, Intrepids make up the second largest group, representing $36 \%$ of employees surveyed. From a rational perspective, Intrepids embrace technology as a means to create professional and business value. Reducing the drudgery of routine work and compensating for understaffing are two of the main benefits. For instance, the project manager who works in a governmental Intellectual Property (IP) Rights agency explained that her group receives many cases every year, with each one taking a lot of time to manage. Al is viewed as a solution to replace a small portion of current work, yet she felt the implementation of Al was still valuable because:

"[AI] helps to ease the bottleneck during the application. The teams that are currently in charge of sorting cases have other administrative tasks as well, and we currently have hiring freezes. [If this does free up labor], then the team may transit to be patent auditors. We always have more work than people."

By using Al, her team would be able to process applications or take on other administrative tasks to improve the timeliness and quality of their work.

Intrepids' emotional attitudes toward Al are also positive. Anticipation and optimism were two frequently mentioned feelings. For instance, the administrative manager continued her observations:

“Young people are actually looking forward to RPA (Robot Process Automation) as they don't really want to do the repetitive, dull work that they have to do on a daily basis now."

This quote demonstrates feelings of eagerness to be released from the drudgery of certain tasks. Employees may also hope that such freedom will allow them time for more interesting, creative, and thoughtful work. Our research suggests Intrepids embrace Al because they are optimistic about how Al and humans can work together. A junior bank clerk who had just graduated from college, expressed his reasons for optimism in this way:

"I saw in the news that there is this 'bankerless bank', where everything is automated, but I think there are still many businesses that need human intervention, when the 
process is complex, or where there is an anomaly. . . . So I think human and machines help each other. Machines help human save time, and humans solve problems machines can't. And that's good. I'm pretty optimistic."

His optimism stemmed from a belief that human and $\mathrm{Al}$ complement each other. With Al taking away the mundane part of the job, humans can specialize in value-adding activities and provide a human touch:

"I think Al is powerful, but I feel human beings are smarter than Al. I think automation saves a lot of labor, but machines cannot chat and develop a relationship with clients. Clerks are important because there is warmth."

While optimistic, Intrepids do not hold unrealistic expectations about Al. Objectively, they assess the technology's strengths and limitations relative to the humans interacting with the Al system. For instance, the junior bank clerk expressed a willingness not only to use the Al, but also to train it. He was eager to understand how Al treats data and makes decisions so that he could incorporate that knowledge into his own evaluations. This type of human-machine collaboration will be essential for fine-tuning Al algorithms to achieve better performance.

\section{Resistance is futile for Al Reticents}

Al Reticents, who represent about $8 \%$ of our sample, are pragmatic and rational about the benefits of Al. They see Al as highly developed in terms of both operational and cognitive capabilities, but remain worried about our future with Al. The bank IT Director we spoke to explained it this way:

"In a lot of industries now, Al is fully capable of dealing with basic, simple tasks, such as first-round interviews, insurance claims etc. In the short-run, 3 to 5 years, Al still can't replace the majority of jobs, unless it is high repetitive and involves minimum knowledge . . . But in the long run, 10-20 years from now, I think everyone should be worried about the potential impact of Al on our life."

Although the Director acknowledges the business benefits of using Al for the automation of routine tasks, he expresses fears people may have regarding the future impact of the technology.

In terms of behavioral responses, Reticents are less inclined to engage in using $\mathrm{Al}$ as compared to the Intrepids, but they are also less likely to look for a job elsewhere, as compared to Dissenters. Some employees in this category seem resigned to the fact that they will have to adjust and learn to use $\mathrm{Al}$, as the IT Director continued:

"As an employee, you have to learn Al skills despite your dislike for it to have a chance, unless you retire. This is the trend, and our likes or dislikes are irrelevant. Personal resistance is futile."

Other participants, including bank staff echoed the same conclusion, saying "there is no use resisting it [Al transformation]. You just have to adapt to it." As a result, he was planning to leverage internal openings to make a career transition to IT project manager.

\section{Al Skeptics want Al capabilities to improve}

Skeptics represent about $10 \%$ of the sample and have conflicting rational and emotional attitudes. Skeptics remain relatively committed to their organizations, having lower turnover intentions and higher intentions to use Al than Dissenters and Reticents.

Like the Intrepids, Skeptics are optimistic about the future of work and see the advancement of $\mathrm{Al}$ as a generally positive for human beings. For instance, an IT manager at a mid-sized bank, affirmed that " $A l$ is a good thing" as it has a wide range of possible applications in the banking industry that could save considerable cost and manpower and enable people to "focus on the more challenging parts of work."

Even though they are favorable toward Al at an emotional level, Skeptics evaluate Al's current capabilities less favorably than other employees and do not consider the technology mature enough to fully deliver expected results. The shortcomings of Al were a particular focus for a bank IT manager, as he admitted that he thought it would be difficult for Al to "completely replace a job, even it is simple right now." He explained why he felt Al was not a good solution in some of the areas in his bank in this way:

"The bank does not plan to introduce Al trading as we are afraid that based on basically the same set of available historical data, Al algorithms will make very similar predictions, which would reinforce the market trend and a more volatile market, leading to unpredictable and unexpected cases like the 2010 flash crash."

Skeptics also hold low perceptions of the cognitive capabilities of Al. This assessment comes through, as the IT manager continued to explain:

"with humans, this could be avoided as human beings think so diversely. When Al makes mistakes, nobody understands why, and there is not even time to safeguard it from making mistakes."

As noted above, the applications of $\mathrm{Al}$ in use today are 'narrow' Al and are still evolving quickly. As the capabilities in cognitive and operational capabilities grow, Skeptics are likely to see increasing value of Al for their organizations.

\section{STRATEGIES FOR EFFECTIVELY MANAGING ORGANIZATIONS THROUGH AI ADOPTION}

\section{Strategy 1. know your people}

Identifying the Intrepids, Reticents, Skeptics and Dissenters within an organization will allow managers to take necessary actions to mobilize, convert, and retain valuable human resources. Getting to know employees' attitudes toward Al requires careful listening. Managers can gauge their employees' profiles by inviting them to participate in informal, non-evaluative group discussions in which they ask open questions, such as what do you think are the pros and cons of Al, what makes you excited and worried about the growth of $\mathrm{Al}$, and how do you imagine the future with Al. The responses to these questions could reveal employees' rational and 
emotional attitudes toward Al, allowing managers to make an educated guess as to which employees are likely to be part of each profile, cognizant as well that employees' attitudes may change over time. Armed with this knowledge, managers can then implement different strategies according to the recommendations below.

Leverage the Intrepids: The introduction of $\mathrm{Al}$ is an organizational change event. Identifying and supporting champions, the individuals who actively and enthusiastically promote the technology, are important to the success of any innovation (Selected bibliography 7). Therefore, leaders should involve Intrepids as champions for the planned Al implementation at different stages to persuade, lead, showcase, and promote the change. Besides fulfilling the role of champions to enhance awareness and understanding of Al, Intrepids can provide social support for other employees affected by Al, building a trusting environment and easing emotional responses, particularly for Dissenters and Reticents.

Look after the Dissenters: Organizations should take care to ensure that the Dissenters' concerns are addressed. Despite their relatively negative attitudes toward Al, Dissenters are still likely to engage in using Al to some extent, if they decide to stay within the organization. Changes are daunting and sometimes people become so afraid that they would rather escape by leaving the company than facing it (Selected bibliography 8). Organizations must communicate clearly regarding the redeployment of human capital. Organizations need to stress that Al implementation does not equate directly with job cuts and that other opportunities for interesting work will be created within the organization. Otherwise, employees' fears will increase, and they will look for opportunities elsewhere. Organizations must also provide proper training to employees as they transition to new roles.

Listen to the Skeptics: Skeptics hold negative views about Al's capabilities, and some of them are right! Al is not omnipotent, and there are currently many limitations of $\mathrm{Al}$, as well as technical challenges to implementing it. Skeptics may see hidden costs or risks that are not evident to others. Thus, managers must be committed to understanding why Skeptics hold lower perceptions of the operational and cognitive capabilities of Al, take them seriously, and search out solutions for overcoming weaknesses with the technology.

Convert the Reticents: If possible, organizations should try to convert Reticients into Intrepids. At a rational level, Reticients see the benefits of Al for the organization. Their reluctance is based on discomfort about the anticipated adverse outcomes associated Al. Organizations are advised to position $\mathrm{Al}$ as complementary, rather than as a replacement for workers. This means ensuring Al applications supplements human intelligence and allow people to concentrate on value-adding activities. In so doing, anxiety and apathy could be transformed into anticipation and engagement.

\section{Strategy 2. pay attention to the emotional side}

How do we look after the Dissenters and convert the Reticents? The key lies in tending to the emotional side of employee attitudes. Organizational leaders must pay attention not only to what employees think about Al, but also how they feel about Al. Our research demonstrates that employees at all levels in organizations are concerned to some extent about the future of Al. Employees' concerns can be categorized into two types: worries about changes at work, such as job security and work content; and worries about Al's impact on humanity, such as devaluing human intelligence and relationships. Leaders need to address both concerns.

To ease these concerns, first and foremost, organizations need to always value people and human dignity, which includes positioning $\mathrm{Al}$ as complementary to human activities and knowledge. Tactical measures should include addressing their employees with clear communication about the organization's approach, especially when the primary goal of introducing $\mathrm{Al}$ is to enhance business value and performance, not to reduce human labor. Meanwhile, organizations should also try to create value-adding jobs for their employees in all job functions and provide support in the form of training to employees who transition to new positions.

\section{Strategy 3. build Al applications that deliver}

Whether the Al implementation is well received or actively resisted by employees hinges on organizational efforts to develop favorable perceptions through planning and communicating key aspects of the system. What do users expect from Al systems? We provide the following insights from our research.

The usual stuff still matters: The usual performance metrics for enterprise systems still matter in the case of Al. Users expect Al applications to be flexible, reliable, and able to integrate different sources of data. Al applications must perform better and facilitate the work of employees, rather than creating additional challenges or inefficiencies. Both top managers and employees might get caught up in the hype of $\mathrm{Al}$ and feel pressure from vendors to implement Al solutions, but it is essential that Al solutions address real problems. IT best practices in terms of capturing user needs, fostering collaboration between developers and users, and embracing experimentation are highly recommended to show value of the solution and engage with employees who will be required to use the Al application. Early project failures where Al fails to deliver on basic expectations are likely to set back the organization's progress.

The distinctiveness of $\mathrm{Al}$ also matters: $\mathrm{Al}$ is not just another functional application or enterprise system. Al offers capabilities that we are just beginning to imagine: autonomous vehicles, employee-less bank branches and stores, robotic surgeries, and the list goes on. However, the cognitive capabilities of Al are still imperfect and untested. Al technology faces unique challenges, such as the ability to understand contexts, process natural language, and conduct reasoning (Selected bibliography 9). Because of these capabilities, people will respond differently to Al and expect more from it. Further technological development is needed, but that is not enough. Organizational governance structures must also be reviewed and adjusted, societal norms will need to change, and new regulations and laws will be enacted. The inability to overcome the distinctive 
challenges of Al could render Al applications ineffective, or worse. Thus, organizations should implement responsible innovation principles (Selected bibliography 10) within their Al projects to ensure all stakeholder concerns - economic, social and environmental - are taken into account.

\section{CONCLUSION}

Al has the potential to propel business forward, but does not come without risks. Although the quality and performance of a system is the usual focus, leaders should also pay particular attention to employees' perceptions of Al, concerns regarding the technology, and attitudes, as these factors influence whether employees will fully engage in the Al journey or leave the organization and take critical knowledge and skills with them. Following the three proposed strategies will help organizations navigate this exciting, but challenging passage to the era of Al.

Funding: This work was supported by the Ministry of Science and Technology of Taiwan, which provided a grant for the data collection (Funding number: 107-2628-H-011 $-001-M Y 2$ ) 


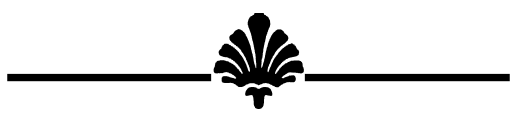

\section{SELECTED BIBLIOGRAPHY}

[1] For further description of artificial intelligence, see Brundage, M., Avin, S., Clark, J., Toner, H., Eckersley, P., Garfinkel, B., Dafoe, A., Scharre, P., Zeitzoff, T. Filar, B. 2018. "The Malicious Use of Artificial Intelligence: Forecasting, Prevention, and Mitigation" available at https:// www.eff.org/files/2018/02/20/malicious_ai_report_final. pdf; Brynjolfsson, E., and McAfee, A. 2017. "The Business of Artificial Intelligence" available at https://starlab-alliance. com/wp-content/uploads/2017/09/The-Business-of-Artificial-Intelligence.pdf; Chui, M., and Malhotra, S. 2018. "Al Adoption Advances, but Foundational Barriers Remain" available at https://www.mckinsey.com/featured-insights/artificial-intelligence/ai-adoption-advances-but-foundationalbarriers-remain\#; and Joshi, N. 2019. "7 Types of Artificial Intelligence" available at https://www.forbes.com/sites/ cognitiveworld/2019/06/19/7-types-of-artificial-intelligence/\#54600188233e.

[2] Bohannon, J. 2015. "Fears of an Al pioneer." Science, 349(6245), 252.

[3] More details can be found in: Frey, C.B. and Osborne, M.A. 2013. "The Future of Employment: How Susceptible are Jobs to Computerisation, University of Oxford." Available online at https://www.oxfordmartin.ox.ac.uk/downloads/ academic/The_Future_of_Employment.pdf, and The World Bank. 2019. "The Changing Nature of Work.” Available online at http://documents.worldbank.org/curated/en/ 816281518818814423/pdf/2019-WDR-Report.pdf. For an interesting commentary on Al deployed in human resources: Hirsch, P.B. 2019. “Tinker, Tailor, Soldier, Spy.” Journal of Business Strategy, 40(4), 53-56.

\section{CREDIT AUTHORSHIP CONTRIBUTION STATEMENT}

Yu-Qian Zhu: Conceptualization, data curation, formal analysis, funding acquisition, methodology, project administra-
[4] Lazarus, R.S., and Folkman, S. 1984. Stress, Appraisal and Coping, New York: Springer.

[5] For more information on how employees' perceptions of resources affect their coping, see: Fadal, K. J., \& Brown, S. B. 2010. "Information Systems Appraisal and Coping: The Role of User Perceptions." Communications of the Association for Information Systems, 26(1), 1-22.

[6] For a discussion of trust, see: Davenport, T.H. 2019. “Can We Solve Al's' Trust Problem'?" MIT Sloan Management Review, 60(2), 1-5.

[7] Howell, J.M. and Higgins, C.A. 1990. "Champions of change: Identifying, understanding, and supporting champions of technological innovations." Organizational Dynamics, 19(1), 40-55.

[8] Neves, P. 2009. "Readiness for change: Contributions for employee's level of individual change and turnover intentions." Journal of Change Management, 9(2), 215-231.

[9] For an in-depth explanation of these challenges, see: "Context, Language, and Reasoning in Al: Three Key Challenges." MIT Technology Review. Available online at : https://www.technologyreview.com/s/602658/context-language-and-reasoning-in-ai-three-key-challenges/

[10] The responsible innovation framework has four main principles (anticipation, reflexivity, inclusion and responsiveness) to ensure that social and ethical considerations are taken into account. For more information, see: Stilgoe, J., Owen, R. and Macnaghten, P. 2013. "Developing a framework for responsible innovation." Research Policy, 42(9), 1568-1580.

tion, resources, writing-original draft, writing-review \& editing. Jacqueline Corbett: Conceptualization, formal analysis, writing-original draft, writing-review \& editing. Yi-Te Chiu: Conceptualization, formal analysis, writing-original draft, writing-review \& editing.

Yu-Qian Zhu (Department of Information Management, National Taiwan University of Science and Technology, No.43, Keelung Rd., Sec.4, Da'an Dist., Taipei City 10607, Taiwan (R.O.C.), +886-2-2737-6772 Email: yzhu@mail. ntust.edu.tw)

Jacqueline Corbett (Faculty of Business Administration, Université Laval, Pavillon Palasis-Prince, 2325 rue de la Terrasse, Quebec, QC Canada G1V 0A6, +01 (418) 656-1213 Email: jacqueline.corbett@fsa.ulaval.ca (Corresponding author))

Yi-Te Chiu (Wellington School of Business and Government, Te Herenga Waka-Victoria University of Wellington, PO Box 600, Wellington 6140, New Zealand, +64-4-463-5689 Email: yi-te.chiu@vuw.ac.nz) 